\title{
Potential clinical and serological predictors of chronic spontaneous urticaria relapse in patients under omalizumab treatment
}

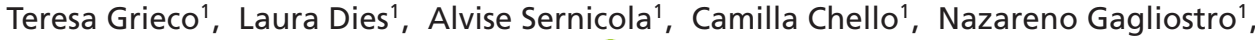 \\ Giorgia Carnicelli \& Giovanni Paolino*,1 iD \\ 'Dermatologic Clinic, Sapienza University of Rome, Viale del Policlinico 155, 00161 Rome, Italy \\ *Author for correspondence: Tel.: +39064 997 6901; Fax: +39 064462 104; paolgio@libero.it
}

Background: Omalizumab is not considered a disease-modifying drug and, accordingly, a large proportion of patients experience a relapse following withdrawal from treatment. Patients \& methods: A total of 42 patients who underwent at least one cycle of treatment with omalizumab were enrolled. Two groups of relapsed and not-relapsed subjects were compared. Then, patients were divided into subgroups. Results: Female patients relapse more frequently than male subjects. Patients who relapsed complained a long duration of disease, while patients who did not relapse had short a history of disease. Very early responders are thought to have a high recurrence rate. Basal IgE levels were increased in early responders and cholesterol levels were high in very early responders, who relapse following withdrawal from omalizumab. High D-dimer levels were observed in late responders. Conclusion: The identification of clinical and serological predictors will play a pivotal role in the future management of patients treated with omalizumab.

First draft submitted: 2 April 2020; Accepted for publication: 10 August 2020; Published online:

7 September 2020

Keywords: angioedema $\bullet$ biomarkers $\bullet$ cholesterol $\bullet$ chronic spontaneous urticaria $\bullet$ D-dimer $\bullet$ histamine $\bullet \operatorname{lgE} \bullet$ mast cell • omalizumab • relapse

Chronic spontaneous urticaria (CSU) is a common skin disorder characterized by the spontaneous onset of wheals, with associated itch and/or angioedema, lasting for six or more weeks [1]. CSU is estimated to affect around 50 million people, with symptoms that heavily impact on quality of life [2,3]. To date, the pathophysiology of CSU is only partially understood. Histamine appears to be the central mediator of CSU: a massive release of this molecule from local basophils and mast cells occurs in the disease, reason why anti-H1 antagonists are highly effective in treating CSU [4-8]. At the same time, an increased production of cytokines of the TH2 subset, mast cell proteases, IL- 8 as well as IFN- $\gamma$, TNF- $\alpha$ and IL- 6 cytokines, is involved in the pathogenesis of CSU [9].

Basophils and mast cells are key players in the pathogenesis of CSU, although the mechanisms underlying their overactivation are still not fully understood. More than one mechanism of autoimmunity has been proposed for the pathogenesis of CSU, encompassing the spectrum of type II and type I autoimmune reactions.

According to the Type II autoallergy model, IgG auto-antibodies (IgGAABs) binding the $\alpha$-subunit of the high-affinity IgE receptor FceRI are detected in a subgroup of patients with CSU. IgGAABs are responsible for the direct basophil and mast cells activation and degranulation, which relies on complement acting as major amplifier of the histaminergic cascade [10-12]. Autoimmunity related to CSU is based on the presence of circulating histamine-releasing IgGAABs directed either against FcERI $\alpha$ on mast cells, basophils or against IgE [13-16].

Type I-autoallergy was recently identified to be mediated by specific IgE-autoantibodies (IgEAABs) targeting autoallergens such as thyroperoxidase, double-stranded DNA and IL-24 [10,11,13]. Coagulation may be involved in up to $50 \%$ of patients with severe CSU, that show signs of activation of the coagulation/fibrinolysis system. Hyperexpression of tissue factor by activated eosinophils could act as initiator of the extrinsic pathway, which is primarily implied, while the intrinsic pathway has a secondary role [17-19]. This pathologic mechanism is thought to correlate with severity of CSU $[20,21]$ and supported by experimental evidence that thrombin, the final enzyme of the coagulation cascade, increases vascular permeability and induces mast cell degranulation [22,23]. 
Omalizumab, a recombinant humanized monoclonal IgG antibody targeting free IgEs, is an effective and safe treatment for patients with CSU [1]. Omalizumab is registered by the US FDA and the EMA since 2014 for the treatment of patients aged 12 years and older [24,25]. The Italian Medical Agency (AIFA) restricts the prescription of omalizumab (300 mg/every 4 weeks) only to CSU patients with inadequate response to treatment with antihistamines. The mechanisms for the efficacy of omalizumab in the treatment of CSU are multiple and still have to be fully elucidated. Among the most accepted actions, omalizumab is able to induce a decrease of free IgE levels, together with the downregulation of FceRI on basophils and mast cells, which take place at different times during omalizumab treatment [26-28]. Response to omalizumab may be observed at an early or late time point following administration of the drug, suggesting that different mechanisms affect the rate of response [29-31].

The aim of our monocentric observational study is to describe the clinical and serological features of relapsing patients with CSU. In relation to their different timing of response to omalizumab, patients are classified into three groups: very early responders (VER), early responders (ER) and late responders (LR) [30].

\section{Patients \& methods}

We performed a monocentric observational study on subjects with CSU resistant to first- and second-line antihistamine therapy, eligible for treatment with omalizumab according to EAACI guidelines [1].

A total of $42(n=42)$ adult patients who had completed at least one course of treatment with omalizumab for CSU were enrolled in this study. Subjects were selected among 153 patients, 43 males and 110 females, aged above 18 years, who consulted our dermatology department with a diagnosis of CSU (from 1 September 2016 to 31 October 2019).

A total of 116 of them (33 males and 83 females) are currently under treatment follow-up for CSU. The disease was diagnosed following the current criteria of the EAACI guidelines, requiring a history of spontaneous urticaria for 6 weeks or longer, with relative treatment. A total of 54 ( $\mathrm{n}=54)$ of our patients $(15$ males and 39 females) resulted unresponsive to first- and second-line therapy with second-generation ant-H1 antihistamines and were candidate to omalizumab treatment. Patients were thoroughly informed on the risks and benefits of the proposed treatment, as well as on the alternative treatment options, and each of them signed the informed consent before the initiation of treatment. According to national AIFA recommendations, patients are treated with omalizumab $300 \mathrm{mg}$ every 4 weeks for a first 6-month course of therapy. Patients who experience disease relapse, identified according to EAACI guidelines by a UAS7 score above 16, are candidates for additional treatment cycles. Concomitant medications were adjusted on a case-by-case basis according to clinical response at monthly follow-up visits. The severity of disease at baseline and the response to therapy were assessed using weekly urticaria activity score (UAS7). According to the response to omalizumab, patients were grouped in VER ( $\mathrm{n}=10), \mathrm{ER}(\mathrm{n}=13)$, LR $(\mathrm{n}=12)$, partial responders $(\mathrm{PR}, \mathrm{n}=3)$, and nonresponders $(\mathrm{NR}, \mathrm{n}=4)$ (Table 1$)$.

VER were defined patients who experienced an immediate improvement of urticaria (UAS $<2$ ) within $24 \mathrm{~h}$ after the first administration of omalizumab; ER those who experienced improvement to UAS7 $<2$ within 1 week from the first administration; LR those in whom improvement occurred after 12 weeks from the beginning of treatment; PR those who had a decrease in UAS7 score but UAS7 > 6; NR those whose UAS7 remained above 16 and mostly unchanged after completion of the first treatment cycle. Each patient was reassessed 8 weeks after completion of treatment. Patients were then followed up for 1 year for the relapse of symptoms (UAS7 > 16).

The main purpose of our study was to identify possible clinical and serological markers of relapse after omalizumab that could be useful in the future therapeutic management and follow-up of CSU.

Patients' clinical data (sex, age at diagnosis, disease duration, history of atopy, autoimmune diseases, angioedema and/or chronic inducible urticaria), laboratory parameters (antinuclear antibodies, basal total serum IgE, antithyroid antibodies, D-dimer, fibrinogen, cholesterol, basophil activation test) and previous therapies were analyzed in order to identify clinical and serological parameters that may be predictive of disease relapse and of the timing of response to therapy with omalizumab.

Laboratory tests were performed at baseline and the following thresholds were used for each parameter: serum $\mathrm{IgE}>100$ kilo unit (KU)/l, D-dimer $>0.90 \mu \mathrm{g} / \mathrm{ml}$, serum cholesterol $>200 \mathrm{mg} / \mathrm{dl}$, fibrinogen $>450 \mathrm{mg} / \mathrm{dl}$, basophil activation test $>15$, antinuclear antibodies $>1: 160$, antithyroid peroxidase antibodies $>16 \mathrm{UI} / \mathrm{ml}$ and antithyroglobulin antibodies $>100 \mathrm{UI} / \mathrm{ml}$. 


\begin{tabular}{|c|c|}
\hline Variables & $n(\%)$ \\
\hline First access for urticaria & 153 \\
\hline - Male & $43(28.1)$ \\
\hline - Female & $110(71.9)$ \\
\hline CSU & 116 \\
\hline - Male & $33(28.4)$ \\
\hline - Female & $83(71.6)$ \\
\hline Patients treated with omalizumab & 54 \\
\hline$<1$ Course & $12(22.2)$ \\
\hline$\geq 1$ Course & $42(77.8)$ \\
\hline - Male & $15(27.8)$ \\
\hline - Female & $39(72.2)$ \\
\hline Response to treatment & 42 \\
\hline - Very early responder $(<24 \mathrm{~h})$ & $10(23.8)$ \\
\hline - Early responder (<1 week) & $13(30.9)$ \\
\hline - Late responder ( $>12$ weeks) & $12(28.6)$ \\
\hline - Partial responder & $3(7.1)$ \\
\hline - Nonresponder & $2(4.7)$ \\
\hline - Adverse reaction & $1(2.4)$ \\
\hline - Lost of efficacy & $1(2.4)$ \\
\hline
\end{tabular}

\begin{tabular}{|c|c|c|c|c|}
\hline Quantitative variables & $\begin{array}{l}\text { Total media (SD); median } \\
\text { ( } \min ; \max ) \\
\mathrm{n}=42\end{array}$ & $\begin{array}{l}\text { Relapse media (SD); median } \\
\text { ( } \min ; \max ) \\
n=28\end{array}$ & $\begin{array}{l}\text { Not relapsed media (SD); } \\
\text { median (min;max) } \\
n=14\end{array}$ & $p$-value \\
\hline $\begin{array}{l}\text { Gender } \\
\text { Female N (\%) } \\
\text { Male N (\%) }\end{array}$ & $\begin{array}{l}31(73.8) \\
11(26.2)\end{array}$ & $\begin{array}{l}24 \text { (77.4) } \\
4(36.4)\end{array}$ & $\begin{array}{l}7(22.6) \\
7(63.6)\end{array}$ & $0.024^{\ddagger}$ \\
\hline $\begin{array}{l}\dagger^{\dagger} \text {-value Mann-Whitney. } \\
\ddagger p \text {-value Fisher's exact tes } \\
\text { Note: Statistical significan } \\
\text { Min: Minimum; Max: Max }\end{array}$ & $\begin{array}{l}\text { expressed in bold. } \\
\text { Imber; SD: Standard deviation }\end{array}$ & & & \\
\hline
\end{tabular}

\section{Statistical analysis}

The frequency of relapse was measured considering, age, sex, clinical and laboratory investigations and response to treatment. Specifically, response to treatment was assessed using UAS7 as one of the following three: VER, ER, and LR. PR and NR were not taken into account for the assessments. Relapse index related to age and sex was assessed with p-value using Mann-Whitney and Fisher's exact test while relapse index related to the different response group was assessed with p-value using Fisher's exact test. Due to the limited number of patients, we did not perform a multiple regression. $\mathrm{p}<0.05$ was considered statistically significant.

\section{Results}

A total of 42 adult subjects, ten males and 32 females, who underwent at least one complete 6-month cycle of treatment were included. Patients were aged mean $(\min ; \max )=48.89(19 ; 83)$ standard deviation $(\mathrm{SD})=18.72$ years. A total of $28(n=28)$ out of 42 patients $(66.6 \%)$ relapsed and 14 maintained remission after 1 year of follow-up $(33.3 \%)$. Though mean age was higher in patients who relapsed (mean $=51.32 ; \mathrm{SD}=18.72$ ) than in those who did not relapse $($ mean $=42.86 ; \mathrm{SD}=18.05)$, this difference was not statistically significant with Mann-Whitney test $(\mathrm{p}=0.140)$. Female sex was associated to a significantly higher frequency of recurrence $(77.4 \%$ in respect to male sex $(36.4 \%)$ using Fisher's exact test $(\mathrm{p}=0.024)$ (Table 2$)$. 


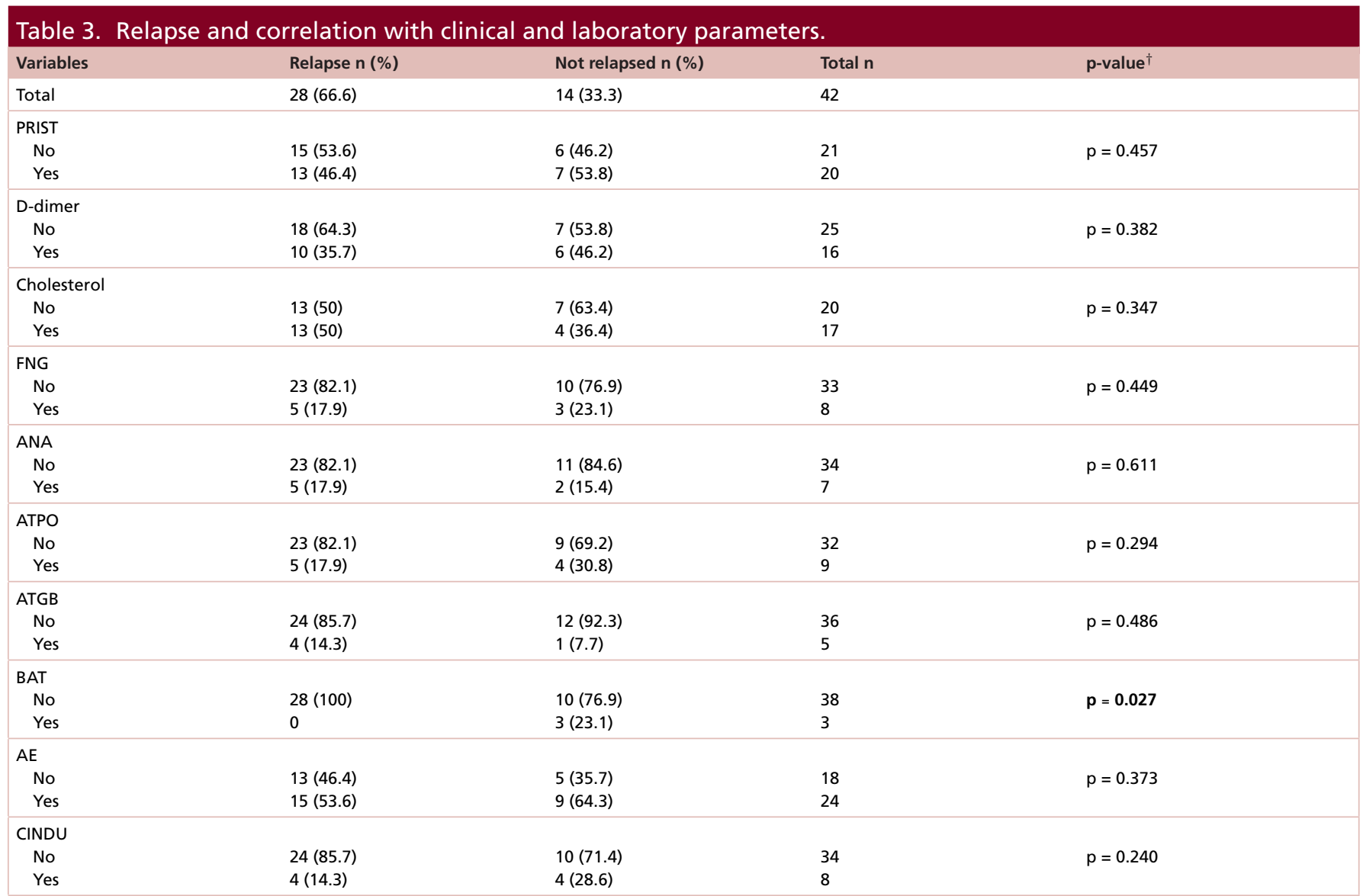

$\dagger^{\dagger} \mathrm{p}$-value Fisher's exact test.

Some patients did not report the required laboratory data.

Note: Statistical significant values are expressed in bold.

AE: Angiooedema; ANA: Antinuclear antibodies; ATPO: Antithyroid peroxidase antibodies; ATGB: Antithyroglobulin antibodies; BAT: Basophil activation test; CINDU: Chronic inducible urticarial; FNG: Fibrinogen; PRIST: Total IgE.

\section{Table 4. Response to omalizumab and correlation with age and sex.}

\begin{tabular}{|c|c|c|c|c|}
\hline Quantitative variables & $\begin{array}{l}\text { Total media (SD); median } \\
\text { ( } \min ; \max ) \\
\mathrm{n}=42\end{array}$ & $\begin{array}{l}\text { Very early media (SD); median } \\
\text { (min;max) } \\
n=10\end{array}$ & $\begin{array}{l}\text { Early responder media (SD); } \\
\text { median (min;max) } \\
n=13\end{array}$ & $\begin{array}{l}\text { Late responder media (SD); } \\
\text { median (min;max) } \\
n=12\end{array}$ \\
\hline $\begin{array}{l}\text { Age } \\
\text { Mean; SD } \\
\text { (min;max) }\end{array}$ & $\begin{array}{l}47 ; 18.72 \\
(19 ; 83)\end{array}$ & $\begin{array}{l}57 ; 19.35 \\
(21 ; 80)\end{array}$ & $\begin{array}{l}44 ; 18.83 \\
(19 ; 78)\end{array}$ & $\begin{array}{l}49.5 ; 19.39 \\
(23 ; 83)\end{array}$ \\
\hline $\begin{array}{l}\text { Age per gender mean }(S D) \\
\text { Female } \\
\text { Male }\end{array}$ & $\begin{array}{l}52.13(18.04) \\
40.47(15.99)\end{array}$ & $\begin{array}{l}60.5(14.87) \\
25.5(6.36)\end{array}$ & $\begin{array}{l}45(20.67) \\
42.5(13.96)\end{array}$ & $\begin{array}{l}52(18.80) \\
34(24.02)\end{array}$ \\
\hline
\end{tabular}

Min: Minimum; Max: Maximum; n: Number; SD: Standard deviation.

The analysis of laboratory and clinical parameters showed an association with relapse only of basophil activation test, that was more frequently positive in patients who did not relapse compared with the relapse group, were no positive results were assessed (Fisher's exact test; $\mathrm{p}=0.027$ ). Other variables showed no statistically significant differences between the two groups of relapse and no relapse (Table 3).

Seven patients were classified as PR or NR and excluded from further assessment. The remaining 35 patients were assigned into three subgroups according to treatment response: VER ( $n=10), \operatorname{ER}(n=13)$ and LR $(n=12)$. Previous analyses were repeated for each subgroup (Table 4). A total 24 of 35 patients (68.6\%) relapsed and nine of ten VER patients (90\%) relapsed suggesting a higher frequency of recurrence compared with ER and LR groups. As far as laboratory data are concerned, values according to different types of responders are shown in Table 5. 


\begin{tabular}{|c|c|c|c|c|}
\hline Variables & Very early responders $\mathrm{n}(\%)$ & Early responders $\mathrm{n}(\%)$ & Late responders $\mathrm{n}(\%)$ & Total $\mathbf{n}(\%)$ \\
\hline \multicolumn{5}{|l|}{ Gender } \\
\hline Female & $8(29,6)$ & $9(33.3)$ & $9(37)$ & $27(77.1)$ \\
\hline \multicolumn{5}{|l|}{ Relapse } \\
\hline No & $1(9.1)$ & $6(54.5)$ & $4(36.4)$ & $11(31.4)$ \\
\hline Yes & $9(37.5)$ & $7(29.2)$ & $8(33.3)$ & $24(68.6)$ \\
\hline$\geq 2$ & $9(25.7)$ & $5(14.3)$ & $8(22.9)$ & $22(62.9)$ \\
\hline Total & $10(28.6)$ & $13(37.1)$ & $12(34.3)$ & $35(100)$ \\
\hline \multicolumn{5}{|l|}{ PRIST } \\
\hline No & $4(25)$ & $5(31.3)$ & $7(43.8)$ & $16(47)$ \\
\hline Yes & $5(27.8)$ & $8(44.4)$ & $5(27.8)$ & $18(54)$ \\
\hline Yes & $7(46.7)$ & $4(26.7)$ & $4(26.7)$ & $15(45.5)$ \\
\hline \multicolumn{5}{|l|}{ FNG } \\
\hline No & $6(21.4)$ & $10(35.7)$ & $12(42.9)$ & $28(82.4)$ \\
\hline Yes & $3(50)$ & $3(50)$ & 0 & $6(17.6)$ \\
\hline \multicolumn{5}{|l|}{ ANA } \\
\hline No & $9(32.1)$ & $10(35.7)$ & $9(32.1)$ & $28(82.4)$ \\
\hline Yes & 0 & $3(50)$ & $3(50)$ & $6(17.6)$ \\
\hline \multicolumn{5}{|l|}{ ATPO } \\
\hline No & $8(29.6)$ & $10(37)$ & 9 (33.3) & $27(79.4)$ \\
\hline Yes & $1(14.3)$ & $3(42.9)$ & $3(42.9)$ & $7(20.6)$ \\
\hline \multicolumn{5}{|l|}{ ATGB } \\
\hline No & $8(25.8)$ & $12(38.7)$ & $11(35.5)$ & $31(91.2)$ \\
\hline No & $8(27.6)$ & $10(34.5)$ & $11(37.9)$ & $29(82.9)$ \\
\hline Yes & $2(33.3)$ & $3(50)$ & $1(16.7)$ & $6(17.1)$ \\
\hline
\end{tabular}

Mean duration of disease before initiating omalizumab was 88 months ( $\min ; \max =2 ; 480)$ in patients who relapsed. All patients who did not relapse had a duration of disease ranging between 2 and 18 months.

\section{Discussion}

The pathogenesis of CSU takes into account a complexity of disease mechanisms, many of which are yet to be understood. Autoimmunity likely plays a role both in the pathogenesis of disease and in the response to omalizumab. The clinical observation of early response following first administration of omalizumab suggests the involvement of still unknown immunological mechanisms in the pathogenesis of CSU and in the response to therapy [32].

Omalizumab is not considered a disease-modifying drug and, accordingly, a large proportion of patients experiences a relapse following withdrawal of treatment [33-35]. In our study, $66.6 \%$ of patients relapsed after a successful cycle of therapy and needed further cycles of omalizumab.

Patients that do not relapse may have reached a spontaneous remission of the disease. We hypothesize that the relapse population subgroup is mainly represented by patients with a long-standing history of CSU. 
Our results show that frequency of relapse is higher in females than in males. A tendency to relapse was also observed in relation to age, although the association was not statistically significant. From the evidence gathered, we could infer that sex and age are relevant parameters in preclinical patient evaluation. Concurrent angioedema or chronic inducible urticaria occurred indifferently in relapsing and nonrelapsing subjects.

According to our results, $23.8 \%$ of patients showed treatment response within $24 \mathrm{~h}$ (VER) and $30.9 \%$ within 1 week (ER) after the first administration of omalizumab. Interestingly, VERs seem to be also the ones to experience high rates of recurrence after withdrawal from treatment, requiring therefore additional cycles of omalizumab. We also focused our attention on the clinical severity of CSU, inferring that patients with high skin disease burden, measured as number of urticarial lesions and disease persistence, are the ones to show a prompt response after the first injection of omalizumab; these patients however also show a constant relapse rate within the first 2 months from the end of the treatment cycle.

In accordance with our findings, Ertas et al. showed that high total serum IgE levels seem to be linked to a faster relapse after discontinuation of omalizumab therapy in patients with CSU [36]. The same study also shows that timing of response to omalizumab therapy is associated with the rate of recurrence.

Our results showed high basal IgE levels (above $100 \mathrm{KU} / \mathrm{l}$ ) in ER patients. These patients were also the ones who showed frequent occurrence of relapse following the end of the cycle.

Interestingly, high cholesterol levels - over $200 \mathrm{mg} / \mathrm{dl}$ - were recorded in VERs; as already pointed out, these patients were early relapsing patients after treatment dismission.

In addition to baseline IgE levels, also D-dimer levels are reported to be higher in responders to omalizumab compared with nonresponders [37]. In our sample, D-dimer levels were elevated above $0.90 \mu \mathrm{g} / \mathrm{ml}$ in LRs.

A study from Asero et al. demonstrated that elevated D-dimer levels are associated with disease severity [20], however, at present time there are no clear data on the correlation between baseline D-dimer levels and the response rate to omalizumab therapy [38-40]. Also, the relationship between basophil activation test and the response to omalizumab is unclear. A recent study investigated the possible association between the therapeutic success of omalizumab and a negative basophil activation test [40]. Another study reported positive results of basophil activation test and autologous serum skin test in association to late response to omalizumab [41].

Our results showed basophil activation test negativity in the majority of patients, and in all patients who relapsed, but this finding may be attributed to the limited accuracy and standardization of the techniques.

\section{Conclusion}

Current literature on CSU proposed several clinical and laboratory parameters as potential biomarkers of disease activity and response to therapy, while little has been reported on the predictors of relapse [42].

In the era of precision medicine, researchers and clinicians must join efforts to identify all clinical and laboratory markers that may aid in patient management. Predicting not only the response to treatment but also the risk of relapse is necessary to predict the duration of disease and to guide choice of the best drug on a single patient basis. Achieving a tailored therapy approach to the treatment of CSU is expected to significantly improve the quality of life in our patients.

\section{Author contributions}

L Dies enrolled patients, contributed in the conception of the manuscript, read and approved all draft manuscripts during its preparation. A Sernicola contributed to the writing - review and editing. C Chello participated in the selection and registration of patients, completed and analyzed the basic documentation during the study and also read and approved all draft manuscripts during its preparation. N Gagliostro participated in the selection and registration of patients, completed and analyzed the basic documentation during the study and also read and approved all draft manuscripts during its preparation. G Paolino contributed to the conceptualization of the study, improved the article, read and approved all draft manuscripts during its preparation. T Grieco enrolled patients, contributed in the conception of the manuscript, read and approved all draft manuscripts during its preparation.

Financial \& competing interests disclosure

Novartis covered the Open Access publication fees of this article as support to the authors. The funders had no role in study design, data collection and analysis, decision to publish, or preparation of the manuscript. The authors have no relevant affiliations or financial involvement with any organization or entity with a financial interest in or financial conflict with the subject matter or materials discussed in the manuscript. This includes employment, consultancies, honoraria, stock ownership or options, expert testimony, grants or patents received or pending, or royalties.

No writing assistance was utilized in the production of this manuscript. 
Ethical conduct of research

The authors state that they have followed the principles outlined in the Declaration of Helsinki for all human or animal experimental investigations. In addition, for investigations involving human subjects, informed consent has been obtained from the participants involved.

\section{Open access}

This work is licensed under the Attribution-NonCommercial-NoDerivatives 4.0 Unported License. To view a copy of this license, visit http://creativecommons.org/licenses/by-nc-nd/4.0/

\section{Summary points}

- Chronic spontaneous urticaria is a common skin disorder characterized by the spontaneous onset of wheals associated to pruritus and/or angioedema and lasting for 6 or more weeks.

- Omalizumab, a recombinant humanized monoclonal IgG antibody targeting free $\lg E$, is a safe, effective and well-tolerated treatment for patients with chronic spontaneous urticaria.

- The aim of our observational study was to describe the clinical and serological markers of relapse in chronic spontaneous urticaria, which occurs in the majority of patients after discontinuation of omalizumab.

- Patients who relapsed after one cycle of omalizumab are mostly female and may be older than not-relapsed patients.

- Patients who relapsed complained a long duration of disease before initiating omalizumab, while patients who did not relapse had a short history of disease.

- Very early responders achieve remission within $24 \mathrm{~h}$ of omalizumab injection but are thought to have a high recurrence rate.

- Basal IgE level are increased to $>100 \mathrm{KU} / \mathrm{I}$ in early responders, who showed response within 1 week after the first administration of omalizumab and relapse following the end of the cycle.

- High cholesterol levels $>200 \mathrm{mg} / \mathrm{dl}$ are reported in very early responders, who respond after $24 \mathrm{~h}$ from the first administration of omalizumab and usually relapse following withdrawal from treatment.

- High D-dimer levels $>0.90 \mu \mathrm{g} / \mathrm{ml}$, which is associated to disease severity in the literature, were observed in late responders; however, the possible relation to relapse is unclear.

\section{References}

Papers of special note have been highlighted as: • of interest; $\bullet \bullet$ of considerable interest

1. Zuberbier T, Aberer W, Asero R et al. The EAACI/GA2 LEN/EDF/WAO guideline for the definition, classification, diagnosis and management of urticaria. The 2017 revision and update. Allergy 73(7), 1393-1414 (2018).

-. Covers the definition and classification of urticaria and outlines evidence-based diagnostic and therapeutic approaches for different subtypes of urticaria.

2. Weller K, Maurer M, Grattan C et al. ASSURE-CSU: a real-world study of burden of disease in patients with symptomatic chronic spontaneous urticaria. Clin. Transl. Allergy. 5(5), 29 (2015).

- Contributes to the knowledge and understanding of the burden of disease in patients with symptomatic chronic spontaneous urticaria.

3. Maurer M, Staubach P, Raap U et al. ATTENTUS, a German survey of chronic urticaria patients highlighting the burden of disease, unmet needs and real-life clinical practice. Br. J. Dermatol. 174(4), 892-894 (2016).

4. Harvima IT, Levi-Schaffer F, Draber P et al. Molecular targets on mast cells and basophils for novel therapies. J. Allergy Clin. Immunol. 134(3), 530-544 (2014).

5. Hide M, Hiragun M, Hiragun T. Diagnostic tests for urticaria. Immunol. Allergy. Clin. North Am. 34(1), 53-72 (2014).

6. Church MK, Kolkhir P, Metz M, Maurer M. The role and relevance of mast cells in urticaria. Immunol. Rev. 282, $232-247$ (2018).

7. Kikuchi Y, Kaplan AP. Mechanisms of autoimmune activation of basophils in chronic urticaria. J. Allergy Clin. Immunol. 107(6), 1056-1062 (2001).

8. Kaplan AP. Diagnosis, pathogenesis, and treatment of chronic spontaneous urticaria. Allergy Asthma Proc. 39(3), 184-190 (2018).

9. Grieco T, Porzia A, Paolino G et al. IFN- $\gamma /$ IL- 6 and related cytokines in chronic spontaneous urticaria: evaluation of their pathogenetic role and changes during omalizumab therapy. Int. J. Dermatol. 59(5), 590-594 (2020).

10. Altrichter S, Peter HJ, Pisarevskaja D et al. IgE mediated autoallergy against thyroid peroxidase - a novel pathomechanism of chronic spontaneous urticaria? PLoS ONE 6(4), e14794 (2011).

11. Hatada Y, Kashiwakura J, Hayama K et al. Significantly high levels of anti-dsDNA immunoglobulin E in sera and the ability of dsDNA to induce the degranulation of basophils from chronic urticaria patients. Int. Arch. Allergy Immunol. 161, 154-158 (2013). 
12. Asero R, Tedeschi A, Marzano AV et al. Chronic spontaneous urticaria: immune system, blood coagulation, and more. Expert Rev. Clin. Immunol. 12(3), 229-231 (2016).

-. Presents a comprehensive overview of chronic spontaneous urticarial and its pathogenesis.

13. Schmetzer O, Lakin E, Topal FA et al. IL-24 is a common and specific autoantigen of IgE in patients with chronic spontaneous urticaria. J. Allergy Clin. Immunol. 142(3), 876-882 (2018).

14. Grattan CE, Francis DM, Hide M et al. Detection of circulating histamine releasing autoantibodies with functional properties of anti-IgE in chronic urticaria. Clin. Exp. Allergy 21(6), 695-704 (1991).

15. Fiebiger E, Maurer D, Holub H et al. Serum IgG autoantibodies directed against the alpha chain of Fc epsilon RI: a selective marker and pathogenetic factor for a distinct subset of chronic urticaria patients? J. Clin. Invest. 96(6), 2606-2612 (1995).

16. Ulambayar B, Chen YH, Ban GY et al. Detection of circulating IgG autoantibody to FceRI $\alpha$ in sera from chronic spontaneous urticaria patients. J. Microbiol. Immunol. Infect. 53(1), 141-147 (2017).

17. Asero R, Tedeschi A, Riboldi $\mathrm{P}$ et al. Plasma of patients with chronic urticaria shows signs of thrombin generation, and its intradermal injection causes wheal-and-flare reactions much more frequently than autologous serum. J. Allergy Clin. Immunol. 117(5), 1113-1117 (2006).

18. Asero R, Tedeschi A, Coppola $\mathrm{R}$ et al. Activation of the tissue factor pathway of blood coagulation in patients with chronic urticaria. $J$. Allergy Clin. Immunol. 119(3), 705-710 (2007).

19. Cugno M, Marzano AV, Tedeschi A et al. Expression of tissue factor by eosinophils in patients with chronic urticaria. Int. Arch. Allergy. Clin. Immunol. 148(2), 170-174

20. Asero R, Tedeschi A, Riboldi P et al. Severe chronic urticaria is associated with elevated plasma levels of D-dimer. Allergy 63(2), 176-180 (2008).

-. D-dimer can be associated with a severe course in patients with chronic urticaria and for this reason should be always evaluated at baseline.

21. Takahagi S, Mihara S, Iwamoto K et al. Coagulation/fibrinolysis and inflammation markers are associated with disease activity in patients with chronic urticaria. Allergy 65(5), 649-656 (2010).

22. Schaeffer RC, Gong F, Bitrick MS et al. Thrombin and bradykinin initiate discrete endothelial solute permeability mechanisms. Am. J. Physiol. 264(6), 1798-1809 (1993).

23. Razin E, Marx G. Thrombin-induced degranulation of cultured bone marrow-derived mast cells. J. Immunol. 133(6), 3282-3285 (1984).

24. Food and Drug Administration. www.accessdata.fda.gov/drugsatfda_docs/label/2014/103976s5211lbl.pdf

25. European Medicines Agency. www.ema.europa.eu/ema/index.jsp?curl=pages/medicines(human/medicines/000606/human_med_00116 2.jsp\&mid=WC0b01ac058001d124

26. Hill DA, Siracusa MC, Ruymann KR et al. Omalizumab therapy is associated with reduced circulating basophil populations in asthmatic children. Allergy 69(5), 674-677 (2014).

27. Lin H, Boesel KM, Griffith DT et al. Omalizumab rapidly decreases nasal allergic response and FceRI on basophils. J. Allergy Clin. Immunol. 113(2), 297-302 (2004).

28. Beck LA, Marcotte GV, MacGlashan D et al. Omalizumab-induced reductions in mast cell FceRI expression and function. J. Allergy Clin. Immunol. 114(3), 527-530 (2004).

29. Gericke J, Metz M, Ohanyan T et al. Serum autoreactivity predicts time to response to omalizumab therapy in chronic spontaneous urticaria. J. Allergy Clin. Immunol. 139(3), 1059-1061 (2017).

30. Kaplan A, Ferrer M, Bernstein JA et al. Timing and duration of omalizumab response in patients with chronic idiopathic/spontaneous urticaria. J. Allergy Clin. Immunol. 137(2), 474-481 (2016).

- Patients can be divided into early and late responders based on timing of response to treatment but the underlying mechanisms are incompletely understood.

31. Kaplan AP, Gimenez-Arnau AM, Saini SS. Mechanisms of action that contribute to efficacy of omalizumab in chronic spontaneous urticaria. Allergy 72(4), 519-533 (2017).

32. Maurer M, Altrichter S, Bieber T et al. Efficacy and safety of omalizumab in patients with chronic urticaria who exhibit IgE against thyroperoxidase. J. Allergy Clin. Immunol. 128(1), 202-209 (2011).

33. Maurer M, Ros en $\mathrm{K}, \mathrm{Hsieh} \mathrm{HJ}$ et al. Omalizumab for the treatment of chronic idiopathic or spontaneous urticaria. N. Engl. J. Med. 368(10), 924-935 (2013).

34. Kaplan A, Ledford D, Ashby M et al. Omalizumab in patients with symptomatic chronic idiopathic/spontaneous urticaria despite standard combination therapy. J. Allergy Clin. Immunol. 132(1), 101-109 (2013).

35. Saini SS, Bindslev-Jensen C, Maurer M et al. Efficacy and safety of omalizumab in patients with chronic idiopathic/spontaneous urticaria who remain symptomatic on H1 antihistamines: a randomized, placebo-controlled study. J. Invest. Dermatol. 135(1), 67-75 (2015).

36. Ertas R, Ozyurt K, Ozlu E et al. Increased IgE levels are linked to faster relapse in patients with omalizumab-discontinued chronic spontaneous urticaria. J. Allergy Clin. Immunol. 140(6), 1749-1751 (2017). 
-. Proposes IgE as predictive factor for a relapse in patients with omalizumab-discontinued chronic spontaneous urticaria.

37. Cugno M, Genovese G, Ferrucci $S$ et al. IgE and D-dimer baseline levels are higher in responders than non-responders to omalizumab in chronic spontaneous urticaria. Br. J. Dermatol. 179(3), 776-777 (2018).

-. Highlights the importance of evaluation of $\mathrm{IgE}$ and $\mathrm{D}$-dimer in patients with chronic spontaneous urticarial in treatment with omalizumab at the baseline and during relevant follow-up.

38. Asero R, Marzano AV, Ferrucci S, Genovese G, Cugno M. Baseline D-dimer plasma levels correlate with disease activity but not with the response to omalizumab in chronic spontaneous urticaria. Allergy 74(12), 2538 (2019).

- Demonstrates the importance of D-dimer as biomarker for the activation of coagulation cascade and disease activity in chronic spontaneous urticaria but not for the response to omalizumab.

39. Marzano AV, Genovese G, Casazza G et al. Predictors of response to omalizumab and relapse in chronic spontaneous urticaria: a study of 470 patients. J. Eur. Acad. Dermatol. Venereol. 33(5), 918-924 (2019).

40. Ghazanfar MN, Sand C, Thomsen SF. Effectiveness and safety of omalizumab in chronic spontaneous or inducible urticaria: evaluation of 154 patients. Br. J. Dermatol. 175(2), 404-406 (2016).

41. Gericke J, Metz M, Ohanyan T et al. Serum autoreactivity predicts time to response to omalizumab therapy in chronic spontaneous urticaria. J. Allergy Clin. Immunol. 139(3), 1059-1061 (2017).

42. Puxeddu I, Petrelli F, Angelotti F, Croia C, Migliorini P. Biomarkers in chronic spontaneous urticaria: current targets and clinical implications. J. Asthma Allergy. 12, 285-295 (2019). 
